\title{
Home treatment of COPD exacerbations
}

\author{
Dirkje S Postma, Nick H T Ten Hacken, Huib A M Kerstjens, Gerard H Koëter \\ Department of Pulmonology, University Hospital, Groningen, The Netherlands
}

Introductory article

\section{Home treatment of exacerbations of chronic obstructive pulmonary disease by an acute respiratory assessment service}

\author{
J H Gravil, O A Al-Rawas, M M Cotton, U Flanigan, A Irwin, R D Stevenson
}

Background. Exacerbations of chronic obstructive pulmonary disease are a major cause of hospital admissions, but do not require intensive investigation or complex therapy. We investigated the suitability of home care for severe uncomplicated exacerbations. Methods. Over 3-5 years we assessed 962 patients with exacerbations of chronic obstructive pulmonary disease after referral to a hospital respiratory department by their family physicians. All patients had chest radiographs, oxygen-saturation or arterial- 6 gas analysis, spirometry, and physical assessment. Unless admission was thought to be essential, patients were allowed home with a customised treatment package. Each patient was visited daily by a respiratory $\bar{\emptyset}$ nurse who monitored progress and treatment compliance and provided education and reassurance. Findings. 145 (15\%) of 962 required admission at initial referral and 115 (12\%) were admitted later. $653(68 \%)$ patients were managed entirely at home and 49 (5\%) were referred inappropriately. One patient died at home. All patients had severe disease with a mean forced expiratory volume in $1 \mathrm{~s}$ of 1.02 I and 395 (41\%) had required hospital admission in the previous year. Interpretation. After formal assessment in a hospital respiratory unit, many patients with exacerbations of chronic obstructive pulmonary disease can be treated at home by respiratory nurses. (Lancet 1998;351:1853-5)

Respiratory diseases are a major cause of morbidity and mortality in the community. Patients with moderate to severe chronic obstructive pulmonary disease (COPD) are prone to exacerbations and the frequency of these exacerbations increases with the severity of COPD. Exacerbations are the main cause of visits to general practitioners and emergency departments, and of hospital admissions in affluent countries. Patients with COPD have been reported to have on average 1-4 exacerbations per year, and some of these exacerbations lead to hospitalisation 13 Hospital admissions for airway diseases such as asthma and COPD account for about $7 \%$ of all admissions to hospital. In addition, hospital mortality due to an acute exacerbation of COPD is approximately $10 \%$, thereby exceeding current hospital mortality rates for myocardial infarction. The long term outcome after admission to hospital for an exacerbation is rather poor, with $40 \%$ mortality in one year. These figures vary from country to country depending on the health care system and the availability of ICU beds. Overall, the economic burden for society and the personal burden to an individual patient are very high. It is therefore not surprising that studies have been initiated to pay more attention to adequate treatment of exacerbations in and out of hospital, to improvement of management at home and to the prevention of these exacerbations. The article by Gravil and coworkers is an example of the increasing attentipn that is now being paid to the management of COPD 6
One of the best strategies for preventing admission to hospital is prevention of the exacerbation itself. In $\frac{\text { O }}{3}$ this review we will pay attention to the definition of an exacerbation, the causes and consequences of ex- $\frac{0}{3}$ acerbations, and the management, including available $\stackrel{乛}{\circ}$ knowledge on prevention. We will try specifically to address the issue of whether or not exacerbations would be better treated at home.

Definition of exacerbation

Recent guidelines do not give a definition of exacerbations nor do they provide a classification of ex acerbations of COPD based on clinical parameters. 1 . Although many classifications in the literature can be useful for clinical studies, they are not standardised and $\overline{0}$ are rather difficult to use in clinical practice, especially for general practitioners in the home situation.

Mild exacerbations of COPD are generally accepted to represent an increase in symptoms, especially dyspnoea, not necessarily accompanied by increased cough $\frac{0}{0}$ and sputum production which may be more tenacious than usual. The increased sympfomatology forces the $\stackrel{\bar{Q}}{\vec{P}}$ patient to seek medical attention.9 A severe exacerbation is associated with acute respiratory failure especially in patients with impaired lung function, sometimes accompanied by $\mathrm{CO}_{2}$ retention. ${ }^{1} \mathrm{I}_{11}$ It is clear that the latter cannot be easily diagnosed in the general practice setting and it cannot be treated in the home situation. 


\begin{tabular}{|c|c|}
\hline $\begin{array}{l}\text { Measurements at home } \\
\text { and in hospital }\end{array}$ & $\begin{array}{l}\text { Measurements in } \\
\text { hospital }\end{array}$ \\
\hline $\begin{array}{l}\text { Knowledge of provoking factors } \\
\text { History } \\
\text { Previous condition } \\
\text { Duration/progression } \\
\text { Sleeping/eating difficulties } \\
\text { Symptoms } \\
\text { Change in cough } \\
\text { Change in sputum } \\
\text { Increase in dyspnoea at rest } \\
\text { Inability to speak one full sentence } \\
\text { Temperature }>38.5^{\circ} \mathrm{C} \\
\text { Ankle oedema } \\
\text { Respiratory rate }>25 / \mathrm{min} \\
\text { Heart rate }>110 / \mathrm{min} \\
\text { Worsening cyanosis } \\
\text { Use of accessory muscles } \\
\text { Loss of alertness }\end{array}$ & $\begin{array}{l}\mathrm{FEV}_{1}<1 \text { litre } \\
\mathrm{PaO}_{2}<8 \mathrm{kPa}, \mathrm{SaO}_{2}<90 \% \\
\mathrm{PaCO}_{2} \geqslant 6 \mathrm{kPa} \\
\mathrm{Chest}^{2} \text { radiography } \\
\text { White blood cell count } \\
\text { Haemoglobin } \\
\text { Sputum stain/culture } \\
\text { Biochemistry } \\
\text { Electrocardiogram }\end{array}$ \\
\hline
\end{tabular}

Factors which determine the choice between home management or inpatient care other than the severity of the exacerbation are the cause of the exacerbation (for example, severe pneumonia), concomitant diseases, and/or social factors.

\section{Assessments of severity of exacerbation}

Proper management of an acute exacerbation requires information on the previous condition of the patient when stable. Next, a precise assessment of the severity of the current exacerbation is needed. Table 1 shows the assessment of severity of an exacerbation.

\section{PROVOKING FACTORS}

Before assessing the severity of an exacerbation one must first consider the provoking factors (table 2). Common causes of acute exacerbations of COPD are thought to be primary infections (often viral) of the tracheobronchial tree. Their role has been discussed at length in recent years ${ }^{1}-10$ There is general agreement that the major pathogens isolated from sputum during acute exacerbations of COPD are Haemophilus influenzae Streptococcus pneumoniae and Moraxella catarrhalis. ${ }^{10}$ Several studies have now reported that these bacteria are also isolated from patients with COPD in a stable state. The mere presence of bacterial colonisation of the lower airway does not confirm the importance of bacterial infection in the pathogenesis of COPD exacerbations. It might also be a marker of disease severity since it has been shown that there is an association between bacterial colonisation of the lower airway and more severe airway obstruction ${ }^{17}$ It may reflect a balance in which the impaired host defences are able to limit the numbers of bacteria but not eradicate

Table 2 Provoking and aggravating factors of an acute exacerbation of COPD

\begin{tabular}{|c|c|}
\hline Bacterial infection & Inappropriate oxygen administration \\
\hline Viral infection & Stopping treatment \\
\hline Pneumonia & Drugs (tranquillisers, diuretics, etc) \\
\hline Heart failure & Poor nutrition \\
\hline Pulmonary embolus & Respiratory fatigue of the muscles \\
\hline Pneumothorax & $\begin{array}{l}\text { Gastro-oesophageal reflux and/or } \\
\text { aspiration }\end{array}$ \\
\hline Air pollution & $\begin{array}{l}\text { Airway plugging due to excessive mucus } \\
\text { production or inadequate expectoration }\end{array}$ \\
\hline
\end{tabular}

them ${ }^{18}$ Thus, the role of bacterial infections in exacerbations of COPD remains controversial. A metaanalysis showed a minor but significant benefit from antibiotics which led to general advice to use antibiotics for exacerbations ${ }^{10}$ However, a recent negative study carried out in general practice has weakened even further the very cautious recommendation for antibiotic use ${ }^{12} \vec{\Rightarrow}$ The role of viral infection in COPD is also still under $\stackrel{\text { ? }}{+}$ scrutiny. The contribution of viral infections to COPD exacerbations has been variable, ${ }^{1}$ ranging from $4.4 \%$ 음 to $63.3 \%$ depending on the population under study, the $\vec{\nabla}$ severity of exacerbation, and whether it is in hospital or $\varrho$ general practice. Furthermore, only a few studies have used viral serology to diagnose the viral infection. Im- $\overrightarrow{0}$ proved techniques for detection of viral infections will $\overrightarrow{\vec{C}}$ probably change these figures. Nevertheless, influenza $\vec{\omega}$ vaccination is still recommended for patients with COPD since inflyenza is the most important cause of $\vec{x}$ excess mortality ${ }^{16}$

Other factors associated with exacerbations of COPD $\tilde{\delta}$ include pneumonia, pulmonary hypertension, heart fail- $@$ ure, pulmonary embolism, and pneumothorax ${ }^{20}$ Out- $\infty$ door air pollution has also been shgwn recently to 을 increase the hospital admission rates. ${ }^{21}$ Poor nutrition, drugs (especially tranquillisers), aspiration, airway plugging by mucus, and respiratory muscle fatigue, especially in patients with malnutrition, may aggravate the ex- क acerbation. Furthermore, stopping regular medication $\vec{\theta}$ such as diuretics and/or bronchodilators at the patients $₫$ own initiative may increase symptoms. Inappropriate oxygen administration may aggravate an exacerbation since many COPD patients with hypercapnia as well as hypoxia deteriorate when hypoxic respiratory drive is reduced by high oxygen administration.$^{20}$

\section{PATIENT HISTORY}

This is the most important means for deciding on the severity and causation of the exacerbation. The history allows comparison of the current status with the stable $\underset{x}{\tilde{x}}$ state and assessment of whether there has been a gradual $\dot{\sigma}$ increase in symptoms or an acute event. It may also 3 help in diagnosis and management if the patient re- 8 cognises the symptom pattern from previous experience and response to treatment.

Assessment of the severity of an exacerbation is also helped by detecting sleeping and/or eating difficulties 을 as these also indicate a serious situation.

\section{PHYSICAL SIGNS}

Signs that indicate severity include inability to speak one sentence in full, central cyanosis, use of accessory respiratory muscles, paradoxical chest wall movements, inability to lie flat, oedema, and ultimately haemodynamic instability (table 1). A body temperature of $\mathbb{\mathbb { D }}$ $>38.5^{\circ} \mathrm{C}$, a respiratory rate of $>25$ breaths per minute, $\overrightarrow{\mathbb{D}}$ and a heart rate of 110 beats per minute or more $\frac{a}{\sigma}$ are arbitrarycut off points taken to indicate a severe exacerbation ${ }^{11}$ It is questionable whether these are the $\frac{0}{0}$ correct parameters and levels of abnormality for assessment of severity. For instance, a recent study showed $\stackrel{\underline{O}}{\vec{P}}$ that mean body temperature at admission for a severe exacerbation was $36.4^{\circ} \mathrm{C}$. 10 in the introductory article on the management of COPD exacerbations to be discussed in this review Gravil et alf did not use temperature in their algorithm for home or hospital management which may be correct. 
CLINICAL INVESTIGATIONS

Blood gas analysis provides further evidence for the severity of an exacerbation ${ }^{11}$ Arterial oxygen tension $\left(\mathrm{PaO}_{2}\right)$ of $<8.0 \mathrm{kPa}(60 \mathrm{~mm} \mathrm{Hg})$ and/or arterial oxygen saturation $\left(\mathrm{SaO}_{2}\right)$ of $<90 \%$ when breathing air indicate respiratory failure and the need for evaluation and treatment. Changes must, where possible, be interpreted in conjunction with baseline values for an individual patient. Generally, however, a $\mathrm{PaO}_{2}$ below $6.7 \mathrm{kPa}(50$ $\mathrm{mm} \mathrm{Hg}), \mathrm{PaCO}_{2}$ above $9.3 \mathrm{kPa}(70 \mathrm{~mm} \mathrm{Hg})$, and $\mathrm{pH}$ $<7.3$ signifies a life threatening episode possibly requiring ICU management. Gravil et at did not use $\mathrm{SaO}_{2}$ as a parameter for assessing the severity of an exacerbation. Whether this influences their results is not certain since the effect of $\mathrm{SaO}_{2}$ on re-admission was not evaluated.

In a home based setting a general practitioner cannot use blood gas analysis and has to rely on cyanosis. However, this is not a reliable estimate of hypoxaemia. When present, and new for the particular patient, this signifies severity. When absent or unnoticed, hypoxaemia may still be present and the severity of the exacerbation will be underestimated. The European Respiratory Society guidelines therefore advise that, if the severity of an episode is in doubt, assessment should take place in hospital 8

Other aggravating factors should be sgught such as congestive heart failure or pneumonia 20 Thus, chest radiography is necessary when considering a severe exacerbation. Furthermore, sputum bacteriology may help, the white blood cell count and differential cell count may point to a viral or bacterial infection, and a high haemoglobin measurement may suggest longstanding hypoxaemia. An electrocardiogram (ECG) may help in establishing right ventricular hypertrophy, arrhythmias or ischaemia and even pulmonary embolism, especially if a previously normal ECG is available.

Lung function measurements are also recommended in guidelines on the assessment of the severity of an exacerbation 18 Airways obstruction is the conditio sine qua non in the definition of COPD, and obstruction is the factor that is best related to disability and mortality. For instance, in patients with a forced expiratory volume in one second $\left(\mathrm{FEV}_{1}\right)$ of $<0.751$ the mortality rate at one year is approximately $30 \%$, rising to $90 \%$ at 10 years. ${ }^{2}$ Fortunately, airways obstruction as assessed by $\mathrm{FEV}_{1}$ is a very reliable measurement. Airway obstruction is measured as a reduction in $\mathrm{FEV}_{1} / \mathrm{FVC}$ ratio or as a reduced $\mathrm{FEV}_{1}$ to slow vital capacity ratio. Measurement of $\mathrm{FEV}_{1}$ and VC are increasingly accessible to nonrespiratory physicians. However, in many individuals with a severe exacerbation spirometric testing may not be possible. Also, it is not clear how far the level of reduction in $\mathrm{FEV}_{1}$ signifies severity of an exacerbation or its outcome. Some studies have shown that mild exacerbations are not accompanied by a reduction in $\mathrm{FEV}_{1}^{23}$ while others found decreased $\mathrm{FEV}_{1}$ in both mild exacerbation 12 and moderate to severe exacerbations.1.13 A recent study showed that $\mathrm{FEV}_{1}$ levels during an exacerbation did not relate to re-admission within 12 months after the first admission to hospital with an exacerbation of COPD ${ }^{24}$

SUBJECTIVE MEASURES

Doctors react to several components of disease severity. Subjectively, they assess frailty and mental state. Whether it is correct to use these criteria for making a decision to either let a patient stay at home or refer to

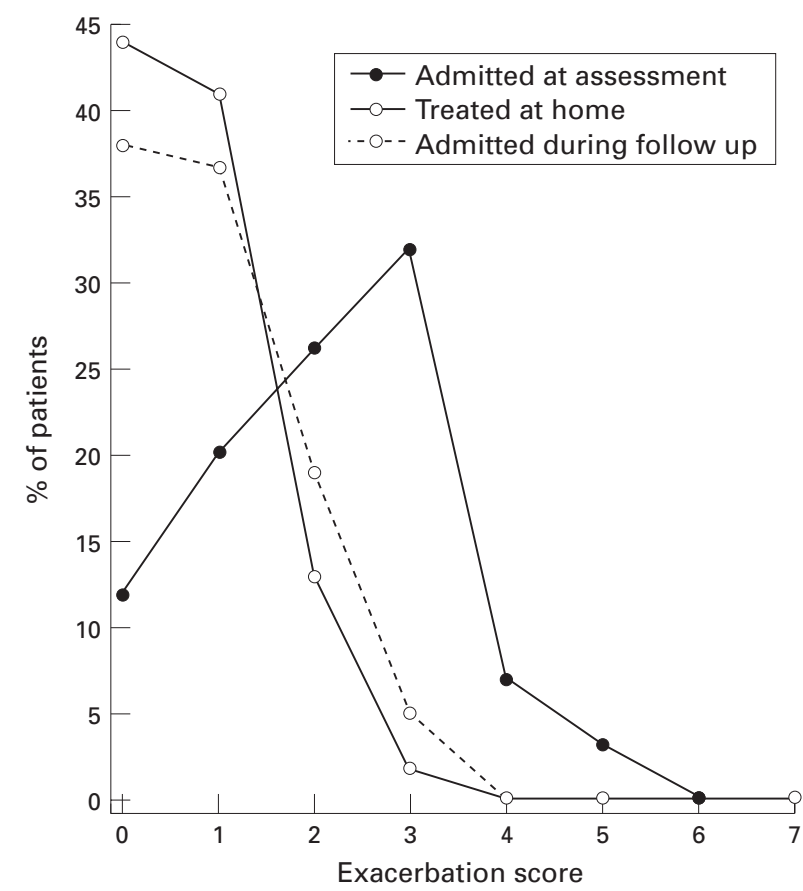

Figure 1 Exacerbation scores for patients with COPD who were admitted immediately to the hospital because of an exacerbation, referred home for treatment and admitted afterwards to the hospital, or referred home fortreatment and staying home. Reproduced from Gravil et a/ $1^{6}$ with permission.

hospital is questionable. These will depend on in- o terpretation and commitment of the general practitioner. The same is true for doctors and nurses working in the outpatient clinic. Gravil et a $t^{6}$ used the degree of dis- $\frac{0}{3}$ ability or frailty in their algorithm for deciding whether $\frac{3}{5}$ or not to admit a patient to hospital in their study on exacerbation assessment by nurses and doctors at the outpatient clinic. They used these even though the 을 grading of severity of the exacerbation was based on $\underset{x}{\mathbb{N}}$ respiratory rate, heart rate, $\mathrm{PaO}_{2}$, abnormal chest radiograph, serious co-morbid condition, altered mental 3 state, and living alone. Unfortunately, the score used 8 did not predict for whether patients were likely to $₹$ be re-admitted after being sent home- $53 \%$ of those 옥 without an exacerbation and $61.7 \%$ of those re-admitted $\supset$ when first sent home had a score of 1 whereas $87.6 \%$ 을 of those admitted immediately had this level of severity, N mean score values being $0.77,0.92$, and 2.11 , respectively. When looking at figure 1 in their article (fig 1), those sent home and re-admitted were indiscernible $\omega$ with respect to their severity score, but only those admitted immediately had scores of 4 or more. There is room for improvement of severity scores in this $\stackrel{\Phi}{\oplus}$ respect, and the use of this type of severity score in clinical practice is not yet advised.

\section{Predictive factors for hospital admission for exacerbations of COPD}

Some patients are prone to frequent exacerbations which have considerable impact on their daily living activities. It is not clear, however, which factors determine the $\stackrel{\bar{O}}{\vec{P}}$ development and severity of an exacerbation. Predictors for admission to hospital are variously reported in the available studies. Some studies have assessed the effect of treatment on the reduction of frequency of hospital admissions. Hospital needs are reduced when home oxygen is instituted in patients with hypoxaemia ${ }^{25}$ One 
retrospective study showed that basal body weight, decline of $\mathrm{FEV}_{1}$ and the rate of deterioration of blood gas tensions were related to the necessity for admission to ICU. ${ }^{2}$ However, the study was retrospective in nature and included only 16 individuals who were all chronically hypercapnic. A recent prospective study investigated 64 patients with moderate to severe COPD with mean $\mathrm{FEV}_{1}$ values of 39 (20)\% predicted ${ }^{27}$ Patients were all followed with three monthly visits and admitted to hospital when they had an acute exacerbation defined by increased symptoms of dyspnoea, cough, or sputum production plus one or more of the following: inadequate response of symptoms to outpatient management which consisted of an increase in the daily doses of inhaled bronchodilators, antibiotics, and a short course of oral steroids; inability to walk between rooms (patient previously mobile); inability to eat or sleep due to dyspnoea; high risk co-morbidity, either pulmonary (e.g. pneumonia) or non-pulmonary; prolonged ( $>15$ days) progressive symptoms before emergency visit; altered mental state; worsening hypoxaemia; new or worsening hypercapnia. Furthermore, patients were admitted to hospital when co-morbid conditions worsened the pulmonary symptoms or when they had unresponsive cor pulmonale. Twenty nine patients were admitted to hospital for an exacerbation, $62 \%$ of these because of worsening hypoxaemia, $59 \%$ because of an inadequate response to outpatient management, and $52 \%$ with severe dyspnoea (inability to walk, eat or sleep); $66 \%$ of these subjects had three or more of the listed criteria for hospital admission. The conclusion of the study was that only $\mathrm{PaCO}_{2}$ and mean pulmonary arterial pressure were independently related to admission to hospital. Markers of airflow limitation (such as $\mathrm{FEV}_{1}$ ) and hypoxaemia were not retained as independent predictors of hospitalisation. However, it is possible that this cohort was too small to detect any influence of the latter two factors on the risk of hospital admission. For instance, a $\mathrm{PaO}_{2}$ below $8.0 \mathrm{kPa}(60 \mathrm{~mm}$ $\mathrm{Hg}$ ) was only present in 15 patients, and even then it was already corrected by oxygen therapy in many individuals. Thus, the best predictors of mortality in COPD - namely, the severity of airflow limitation, advancing age and hypoxaemi ${ }^{22}$ - were not of use for predicting hospital admission. However, as already mentioned, the study group was small. Notwithstanding this, hypercapnia was an important predictor, as expected, yet only 13 patients had a $\mathrm{PaCO}_{2}$ higher than $6.66 \mathrm{kPa}(50$ $\mathrm{mm} \mathrm{Hg}$. Hypercapnia has also been shown to be a good predictor of mortality after discharge from the ICU in patients older than 65 years. Interestingly, Costello et of ${ }^{2}$ have shown that many patients admitted to the ICU with hypercapnia associated with an exacerbation normalised their hypercapnia. However, the patients who remained hypercapnic had a worse long term prognosis than those with reversible hypercapnia.

The best independent predictor for admission to hospital in the study by Kessler et a $\left.\right|^{27}$ was pulmonary hypertension, a marker of the deleterious effects of longstanding alveolar hypoxia on the pulmonary circulation. The authors speculated that home mechanical ventilation might reduce the number of hospital admissions by reducing hypercapnia, as was shown by Leger $e t$ al in a previous study with supervision of nasal intermittent positive pressure ventilation ${ }^{29}$ However, there are also negative studies of home mechanical ventilation and its role is beyond the scope of this review. Home care supervision programmes alone have also been shown to be successful in reducing the need for hospitalisation in these patients 30
One study has looked into risk factors predisposing to frequent exacerbations in patients with moderately severe COPD and an $\mathrm{FEV}_{1}$ of 40 (19)\% predicted. 31. The results showed that daily cough or wheeze and bronchitic symptoms increased the risk for frequent exacerbations (3-8 in one year follow up) but not $\stackrel{2}{x}$ daily sputum production or dyspnoea. In a multivariate $\vec{\Rightarrow}$ analysis patients with frequent past exacerbations, daily $\stackrel{\mathscr{P}}{\stackrel{+}{\mathscr{C}}}$ wheeze, and bronchitic symptoms were at the highest risk for frequent exacerbations. Moreover, a worse dis- $\frac{\bar{D}}{\bar{D}}$ ease specific health status at the last clinic visit in a $\frac{\widehat{D}}{\vec{D}}$ stable state, assessed with the St George's Respiratory $\varrho$ Questionnaire (SGRQ), was strongly related to a higher के number of exacerbations over the one year study period. $\overrightarrow{0}$ The authors found no relationship between the SGRQ $\vec{\overrightarrow{ }}$ outcome and the frequency of exacerbations and the $\vec{\omega}$ need for hospital admission. One recent study found $\stackrel{\curvearrowright}{F}$ a relationship between poor quality of life and re- $\vec{x}$ admission to hospital ${ }^{24}$ Reasons for admissions to hos- + pital are complex and patients are frequently admitted $\tilde{O}$ late in the evolution of the disease, which affects quality $\$$ of life to a large extent. Nevertheless, it seems reasonable $\infty$ to anticipate that a reduction in the frequency of exacerbations may lead to improvement in quality of life in individuals with COPD. It has been shown that poor quality of life is associated with greater use of health care resource $\$^{32}$ and that, when quality of life improves $\stackrel{5}{\oplus}$ even though lung function does not improve, con- $\vec{\theta}$ sultations and hospital admissions decrease. ${ }^{33}$ Whether 8 improvement in quality of life will also lead to a reduction in exacerbations is, however, questionable.

Further studies are needed to determine the extent to which nurse support and education may contribute to recovery or prevention of exacerbations. This effect $\stackrel{\mathbb{D}}{\mathbb{D}}$ is uncertain, but support at a moment of uncertainty for both the patient and his environment would seem important. Appropriate pharmacological treatment and oxygen therapy may further enhance the outcome of COPD exacerbations, which cap also be assisted by nurses. The study by Gravil et dlo is the first to assess $\overrightarrow{0}$ whether home treatment, in association with supervision $\underset{x}{\vec{v}}$ and training by nurses, may be beneficial for treatment $\dot{\sigma}$ of COPD exacerbations. Many practitioners need to 3 decide between home and hospital management of $\dot{\delta}$ COPD exacerbations on a daily basis, and further stud- $₹$ ies may help us decide which is the best choice and for 을 which patients to reduce the number of hospitalisations with better outcomes and lower costs.

\section{Management of an exacerbation} OUTPATIENT MANAGEMENT

The objectives of outpatient or home management have been formulated by Siafakas and Bouro ${ }^{20}$ as follows: $\stackrel{0}{\tau}$ to treat infection, if present; to remove excess bronchial $\stackrel{\Phi}{\Phi}$ secretions; to increase airflow; to improve respiratory 0 muscle strength and thus facilitate cough; to avoid o. adverse events of treatment; to educate patients and $\mathbb{\mathbb { D }}$ their families on the signs of deterioration and the $\mathbb{\mathbb { D }}$ actions to be taken (written instruction). The European guidelines stress that it is important to monitor the patient with a moderate to severe exacerbation and to $\frac{0}{0}$ reassess the effects of treatment within 48 hours. The education and instructions to the patient and/or family $\stackrel{\vec{\partial}}{\vec{F}}$ are stressed.

In general, exacerbations are treated by institution or increase of bronchodilators, systemic corticosteroids, and oxygen when necessary. If infection is likely-for instance, in the presence of fever-antibiotics are started. Otherwise, following observation for 24-48 


\section{LEARNING POINTS}

* Exacerbations of COPD are a major cause of hospital admissions, yet the individual risk factors for hospital admission are not clearly known.

* The role of nurse support and education in prevention of COPD exacerbations should be further studied. * Antibiotics are frequently prescribed in COPD but their usefulness in mild to moderate
exacerbations has not been proved.

* Frequent prescription of antibiotics induces $\beta$-lactamase resistance of bacteria in sputum in patients with COPD.

hours, antibiotics can be started if there is further deterioration. When a patient is known to have severe COPD with hypoxaemia, early antibiotics are appropriate. However, studies have not been done to assess whether this is the best strategy.

Short acting $\beta$ agonists are generally the choice of bronchodilator and their frequency and dosage should be increased to a maximum. Anticholinergics are recommended and may offer greater benefit in combination with a $\beta$ agonist. Their use during an exacerbation can be more efficacious when used via a spacer. Aminophylline use remains controversial for exacerbations and some studies have shown that the toxicity of $\beta$ agonists is increased when combined with aminophylline, but not the efficacy ${ }^{34}$

A recent study in an outpatient setting has shown that oral corticosteroids may accelerate the recovery from an exacerbation, especially with hypoxaemia, and that they may improve spirometric parameters and reduce the treatment failure rate 9 Moreover, a study by Paggiaro and coworker $\beta^{35}$ and the recent results of the ISOLDE study show that inhaled corticosteroids may reduce the number of exacerbations. The same may be true for antioxidants. These may produce benefit by better clearance of sputum. This may be important since mucus production has been shown to be a risk factor for mortality due to pulmonary infections ${ }^{36}$

Initiation of oxygen therapy at home is unwarranted. It may lead to serious complications and must be avoided. If the patient is on long term oxygen therapy a thorough inspection of the apparatus and review of the dosage of oxygen given is recommended. This aspect requires further clinical evaluation.

Recent studies have advocated education as a measure to reduce consumption of health care facilities. Tougaard et $\mathrm{p}$ showed that this is the case in a group of patients with COPD of variable severity. Education on actions to be taken for an incipient exacerbation should include: (1) optimal compliance with medication; (2) avoidance of hypnotics and sedatives; (3) sufficient fluid intake; (4) small and frequent meals if eating is difficult; (5) self-clearance of sputum by adequate cough techniques (in cases of emphysema the forced expiration technique is not advise ${ }^{38}$. The patient and family should have written instructions on the symptoms and signs indicating a worsening condition and the actions to be taken. In this respect there is a note of caution on prescription of antibiotics. A study in patients with COPD showed that increasing the number of antibiotic courses was associated with $a$ higher incidence of $\beta$ lactamase producing bacteria ${ }^{39}$ Further, the number of COPD patients in this study admitted to hospital for an exacerbation of COPD was higher in the group who had $\beta$-lactamase positive strains of Haemophilus influenzae and Moraxella catarrhalis in their sputum than in the group with $\beta$-lactamase negative strains. Antibiotics are probably instituted too frequently during exacerbations.

Referral or home care?

As with many other diseases, it is difficult to give a $\stackrel{\longrightarrow}{\rightarrow}$ simple guide as to which patients with an exacerbation should be seen by the general physician, which should be seen at an emergency department and sent home, $\stackrel{\text { s }}{+}$ and which should be admitted to hospital. These de- $\vec{\theta}$ cisions will probably vary by country and, unfortunately, also by billing systems. In general it is important to $\square$ realise that criteria for patterns of care should be evidence based from controlled studies. So far there is little evidence on which to base the decision process. The best advice remains: when in doubt refer to an $\mathbb{D}$ emergency department. When there is significant deterioration in mental status, increased use of accessory $\frac{0}{3}$ respiratory muscles, and paradoxical abdominal breathing referral is mandatory since any of these symptoms suggests respiratory failure.

Since the staging of exacerbation severity is still not formalised and does not give a clear indication of the $\stackrel{x}{x}$ best treatment, we still need more prospective studies in patients with COPD over a range of severity. This includes the large group of patients under the care of $\delta$ general practitioners, as well as more severe cases with shared care between general practitioners and spe- $\frac{0}{2}$ cialists. Finally, the role of education has to be further $\rightarrow$ explored. If the reduction in hospital use, as shown by Gravil and coworkers ${ }^{6}$ can be translated into a reduction $N$ in the numbers of exacerbations, there will be important $N$ consequences for COPD patients, their families, nurses N and doctors, and for the health economy. 1 Fletcher C, Peto R. The natural history of chronic airflow obstruction.
BMf 1977;1:1645-8.

2 Collet JP, Shapiro S, Ernst P, et al. Effect of an immunostimulating agent on acute exacerbations and hospitalization in patients with chronic obstructive pulmonary disease. Am $\mathcal{F}$ Respir Crit Care Med 1997;156:1719-24.

3 Anthonisen NR, Manfreda J, Warren CPW, et al. Antibiotic therapy in $\mathbb{D}$ exacerbations of chronic obstructive pulmonary disease. Ann Intern $\frac{\mathbb{D}^{\circ}}{4}$ Med 1987;106:196-204.

4 Angus RM, Murray S, Lay JW, et al. Management of chronic airflow obstruction: differences in practice between respiratory and general physicians. Thorax 1994;88:493-7.

5 Connors AF, Dawson NV, Thomas C, et al. Outcome following acute 음 exacerbation of severe chronic obstructive lung disease. Am $\mathcal{F}$ Respir Crit Care Med 1996;154:959-67.

6 Gravil JH, Al-Rawas OA, Cotton MM, et al. Home treatment of exacerbations of chronic obstructive pulmonary disease by an acute respiratory assessment service. Lancet 1998;351:1853-5.

7 American Thoracic Society. Standards for the diagnosis and care of patients with chronic obstructive pulmonary disease: ATS statement. patients with chronic obstructive pulmonary dise
Am $\mathcal{F}$ Respir Crit Care Med 1995;152:S77-S120.

8 Siafakas NM, Vermeire P, Pride NB, et al. Optimal assessment and Siafakas NM, Vermeire P, Pride NB, et al. Optimal assessment and
management of chronic obstructive pulmonary disease (COPD). A consensus statement of the European Respiratory Society. Eur Respir f $1995 ; 8: 1398-420$. 
9 Thompson WH, Nielson CP, Carvalho P, et al. Controlled clinical trial of oral prednisone in outpatients with acute COPD exacerbation. Am f Respir Crit Care Med 1996;154:407-12.

10 Connors AF, Dawson NW, Thomas C, et al for the SUPPORT Investigators. Outcome following acute exacerbations of severe chronic obstructive lung disease. Am F Respir Crit Care Med 1996;154:959-67.

11 Hagedorn SD. Acute exacerbations of COPD. How to evaluate severity and treat the underlying cause. Postgrad Med 1992;91:105-12.

12 Sachs AP, Koëter GH, Groenier KG, et al. Changes in symptoms, peak expiratory flow and sputum flora during treatment with antibiotics of exacerbations in patients with chronic obstructive pulmonary disease in general practice. Thorax 1995;50:758-63.

13 Fletcher CM, Peto R, Tinker C, et al. The natural history of chronic bronchitis and emphysema: an eight-year study of early chronic obstructive lung disease in work

14 Wilson R, Dowling RB, Jackson AD. The biology of bacterial colonization and invasion of the respiratory mucosa. Eur Respir f 1996 9:1523-30.

15 Schlick W. Selective indications for use of antibiotics: when and what? Eur Respir Rev 1992;9:187-92.

16 Rothbarth PH, Kempen BM, Sprenger JW. Sense and nonsense of influenza vaccination in asthma and chronic obstructive pulmonary influenza vaccination in asthma and chronic obstruct

17 Zalacain R, Sobradillo V, Amilibia J, et al. Predisposing factors to bacterial colonization in chronic obstructive pulmonary disease. Eur Respir 7 1998;13:343-8.

18 Wilson R. Bacterial infection and chronic obstructive pulmonary disease. Eur Respir f 1998;13:233-5.

19 Saint S, Bent S, Vittinghoff E, et al. Antibiotics in chronic obstructive pulmonary disease exacerbations: a meta-analysis. $\mathcal{F} A M A 1995 ; 273$ 957-60.

20 Siafakas NM, Bouros D. Management of acute exacerbation of chronic obstructive pulmonary disease. In: Management of chronic obstructive pulmonary disease, A European Respiratory Monograph. Vol 3. 1998: 264-277.

21 Stedman JR, Anderson HR, Atkinson RW, et al. Emergency hospital admissions for respiratory disorders attributable to summer time ozone admissions for respiratory disorders attributable to sum

22 Hodgkin JE. Prognosis in chronic obstructive pulmonary disease. Clin Chest Med 1990;11:555-69.

23 Saetta M, Di Stefano A, Maestrelli P, et al. Airway eosinophilia in chronic bronchitis during exacerbations. Am $\mathcal{F}$ Respir Crit Care Med 1994;150:1646-52.

24 Osman LM, Godden DJ, Friend JAR, et al. Quality of life and hospital re-admission in patients with chronic obstructive pulmonary disease. Thorax 1997;52:67-71.

25 Petty TL. Long-term outpatient oxygen-therapy. In: Petty TL, ed. Chronic obstructive pulmonary disease. New York: Marcel Dekker, 1985 375-88.

26 Vitacca M, Clini E, Porta R, et al. Acute exacerbation in patients with COPD: predictors of need for mechanical ventilation. Eur Respir $\mathcal{F}$

27 Kessler R, Faller M, Fourgaut G, et al. Predictive factors of hospitalization for acute exacerbation in a series of 64 patients with chronic obstructive pulmonary disease. Am f Respir Crit Care Med 1999;159:158-64.

28 Costello R, Deagen P, Fitzpatrick M, et al. Reversible hypercapnia in chronic obstructive pulmonary disease: a distinct pattern of respiratory failure with a favorable prognosis. Am f Med 1997;102:239-44.

29 Leger P, Bedicam JM, Cornette A, et al. Nasal intermittent positive $\overline{\bar{S}}$ pressure ventilation: long-term follow-up in patients with severe $\vec{\Phi}$
chronic respiratory insufficiency. Chest 1994;105:100-5.

30 Clini E, Vitaca M, Foglio K, et al. Long-term home care programmes may reduce hospital admissions

31 Seemungal TAR, Donaldson GC, Paul EA, et al. Effect of exacerbation on quality of life in patients with chronic obstructive pulmonary disease. Am 7 Respir Crit Care Med 1998;157:1418-22.

32 Traver GA. Measures of symptoms and life quality to predict emergent use of institutional health care resources in chronic obstructive airway use of institutional health care resources

33 Cox NJ, Hendricks JC, Binkhorst RA, et al. A pulmonary rehabilitation of program for patients with asthma and mild chronic obstructivce pug

34 Rice KL, Leatherman JW, Duane PG, et al. Aminophylline for acute exacerbations of chronic obstructive pulmonary disease. Ann Intern 987:107:305-9.

35 Paggiaro PL, Dahle R, Bakran L, et al. Multicenter randomized placebo $\infty$ controlled trial of inhaled fluticasone propionate in patients with COPD. Lancet 1998;351:773-80.

36 Prescott E, Lange P, Vestbo J. Chronic mucus hypersecretion in COPD and death from pulmonary infection. Eur Respir F 1995;8:1333-8.

37 Tougaard L, Krone T, Sorknaes A, et al and the PASTMA group. Economic benefits of teaching patients with chronic obstructive pulmonary disease about their illness. Lancet 1992;339:1517-20.

38 Van der Schans CP, Piers DA, Beekhuis H, et al. Effect of forced expirations on mucus clearance in patients with chronic airflow obstruction: effect of lung recoil pressure. Thorax 1990;45:623-7.

39 Sportel JH, Koëter GH, Van Altena R, et al. Relation between betalactamase producing bacteria and patient characteristics in chronic obstructive pulmonary disease (COPD). Thorax 1995;50:249-53. 